\title{
Prediction of Failure Categories in Plastic Extrusion Process with Deep Learning
}

\author{
Fatma Demircan Keskin*(iD), Ural Gökay Çiçekli² (iD) İsmail Doğukan İçli ${ }^{3}$ (D) \\ ${ }^{1,2}$ Ege University/Department of Business Administration, Izmir, Turkey \\ ${ }^{3}$ Ege University/Graduate Faculty of Social Sciences, Izmir, Turkey \\ fatma.demircan.keskin@ege.edu.tr, gokay.cicekli@ege.edu.tr,dogukan.icli@gmail.com
}

\begin{abstract}
Today's manufacturing vision necessitates extracting insights from the data collected in real-time from manufacturing processes. Predicting failures with the predictive analysis of the collected process data and preventing these failures by taking necessary actions before they occur is a key factor in ensuring quality at the desired level, increasing productivity, and reducing costs in production systems. In the literature on predictive analysis of process data, machine learning and deep learning methods have attracted considerable attention, especially in recent years. This study has addressed a multi-class failure classification problem in the plastic extrusion process with a real case study. Classification models have been developed based on Long Short-term Memory (LSTM) as a deep learning method and Multilayer Perceptron (MLP) and Logistic Regression (LR) as machine learning methods to predict the failure categories. In the case study, real data taken from the extrusion process of one of the leading insulation companies operated in Izmir has been used. The final dataset includes actual measurements of seven parameters related to temperature and pressure and failure categories as the target variable. Three failure categories have been identified to define Category 0 (No failure), Category 1 (Filter change), and Category 2 (Feeding failures) states, and coded as 0,1 and 2 in the models, respectively. LSTM, MLP, and LR's performance to predict the failure categories have been evaluated and compared based on accuracy, precision, recall, and F1 Score measures. LSTM is the highest performing among the three methods, with $100 \%$ prediction accuracy for each failure category. On the other hand, LR and MLP have achieved considerable and close results except for Category 1.
\end{abstract}

Keywords: Deep learning, failure prediction, machine learning, plastic extrusion process.

\section{Plastik Ekstrüzyon Sürecinde Derin Öğrenme İle Hata Kategorilerinin Tahmini}

\section{$\ddot{O} \mathbf{z}$}

Günümüz üretim anlayışı, imalat süreçlerinden gerçek zamanlı olarak toplanan süreç verisinden kestirim yapabilmeyi gerektirmektedir. Toplanan süreç verilerinin kestirimci analizi ile hataların tahmin edilmesi ve gerekli aksiyonların alınmasıyla hataların ortaya çıkmadan önlenmesi, üretim sistemlerinde kalitenin istenilen seviyede sağlanması, verimliliğin artırılması ve maliyetlerin azaltılmasında kilit bir faktördür. Makine öğrenmesi ve derin öğrenme yöntemleri, süreç verilerinin kestirimci analizinde, özellikle son dönemlerde büyük ilgi görmektedir. Bu çalışmada plastik ekstrüzyon sürecinde çok sınıflı hata sınıflandırma problemi bir gerçek hayat örneğiyle ele alınmıştır. Problemin çözümü için derin öğrenme yöntemlerinden Uzun-Kısa Süreli Bellek (LSTM) ve makine öğrenmesi yöntemlerinden Çok Katmanlı Algılayıcı (MLP) ve Lojistik Regresyon (LR) kullanılmıştır. Çalışmanın uygulama kısmında, İzmir'de faaliyet gösteren Türkiye'nin önde gelen yalıtım firmalarından birinin plastik ekstrüzyon sürecinden alınan gerçek veriler kullanılmıştır. Nihai veri seti, süreçten alınan sıcaklık ve basınçla ilişkili yedi parametrenin gerçek ölçümlerini ve hedef değişken olarak hata kategorilerini içermektedir. Modellerde Kategori 0 (Hata yok), Kategori 1 (Filtre değişimi) ve Kategori 2 (Besleme hataları) durumlarını tanımlamak için üç hata kategorisi belirlenmiş ve sırasıyla 0,1 ve 2 olarak kodlanmıştır. LSTM, MLP ve LR'nin hata kategorilerini tahmin etme performansı, tahmin doğruluğu, kesinlik, duyarlılık ve F1 skoru metriklerine göre değerlendirilmiş ve karşılaştırılmıştır. LSTM, her hata kategorisi için \%100 tahmin doğruluğu ile en yüksek performansa sahip olmuştur. LR ve MLP, Kategori 1 dışındaki hata kategorileri tahminlerinde başarılı ve birbirine yakın sonuçlar elde etmiştir.

Anahtar Kelimeler: Derin öğrenme, hata tahmini, makine öğrenmesi, plastik ekstrüzyon süreci

\footnotetext{
* Corresponding Author.

E-mail: fatma.demircan.keskin@ege.edu.tr
}

$\begin{array}{ll}\text { Recieved } & : 12 \text { Feb } 2021 \\ \text { Revision } & : 16 \text { Sep } 2021 \\ \text { Accepted } & : 27 \text { Oct } 2021\end{array}$

**This paper is an extended version of the paper published in the Proceedings Book of 11th International Statistics Congress, on 4-8 October 2019. 


\section{Introduction}

Rapid developments in digital technologies have had transformative effects on manufacturing systems and turned them into smart systems. The current industrial vision, Industry 4.0 , has structured an interconnected manufacturing environment and forced companies to reconsider their processes. One of the critical cornerstones of Industry 4.0 and smart manufacturing is collecting real-time data from the plant via sensors and networks and providing value by conducting a data-driven predictive analysis.

Failures may occur in the manufacturing environment due to many causes. Therefore, in smart manufacturing systems, it is critical to monitor manufacturing processes in real-time, predict failures, and take appropriate actions to prevent them from happening to ensure product quality (Tao et al., 2018).

Fault detection and prediction problems in the manufacturing environment have been extensively addressed through machine learning methods (Konar and Chattopadhyay, 2011; Jing and Hou, 2015) and, in particular, deep learning methods with increasing interest recently (Jing et al., 2017; Shao et al., 2017; Zhang et al., 2017a).

Neural networks (Hou, Liu, and Lin, 2003; Quintana et al., 2011) and LR (De Menezes et al., 2017) are among the most widely applied supervised machine learning methods for failure classification and prediction problems using process data.

LR is a supervised machine learning method with a wide range of application areas for prediction problems containing a categorical dependent variable and a set of independent variables (Caesarendra et al., 2010). When the dependent variable has multi-class, like the problem addressed in this study, multi-class LR needs to be employed. The conditional probability $\mathrm{P}(\mathrm{Y}=\mathrm{y} \mid$ $\mathrm{X}=\mathrm{x}$ ) in multi-class $\mathrm{LR}$ is calculated by using Equation (1) (Le Thi et al., 2020):

$$
\mathrm{P}(\mathrm{Y}=\mathrm{y} \mid \mathrm{X}=\mathrm{x})=\frac{\exp \left(b_{y}+W_{:, y^{X}}^{T}\right)}{\sum_{k=1}^{Q} \exp \left(b_{y}+W_{:, y^{X}}^{T}\right)}
$$

where $\left\{\left(x_{i}, y_{i}\right): i=1, \ldots, n\right\}$ is a training set that includes observation vectors $x_{i} \in \mathbb{R}^{d}$ and labels $y_{i} \in$ $\{1, \ldots, Q\}, Q$ denotes the number of classes, $W$ is the $\mathrm{dxQ}$ matrix and $b=\left(b_{1}, \ldots, b_{Q}\right) \in \mathbb{R}^{Q}$. It is aimed to find $\mathrm{a}(\mathrm{W}, \mathrm{b})$ pair that maximizes the total probability of the correct class y to which $x_{i}$ belongs. The negative log-likelihood function needs to be minimized to obtain (W,b) estimation (Le Thi et al., 2020).

MLP, one of the most employed neural network techniques, especially for the problems related to production control (Cadavid et al., 2020), contains input and output layers of units and hidden unit/units' layers between them (Fallah, Mitnitski and Rockwood, 2011). In MLP, the units are organized in a feedforward layered topology (Venkatesan and Anitha, 2006). MLP uses various nonlinear functions to convert $\mathrm{n}$ inputs to $\mathrm{l}$ outputs. In Equation (2), the activation function used to determine the network output is given (Yilmaz and Kaynar, 2011):

$$
x_{0}=f\left(\sum_{h} x_{h} w_{h o}\right)
$$

where $\mathrm{f}$ denotes the activation function, $x_{h}$ is $\underline{h}$ th hidden layer node's activation and $w_{h o}$ is the $\bar{h}$ th hidden layer node and $o$ th output layer interconnection.

Deep learning, which has significant successful applications in many different areas such as text detection and classification, speech and image recognition, provides advanced analytical opportunities for analyzing big data obtained from manufacturing processes (Wang et al., 2018). There have been different deep learning approaches, including Convolutional Neural Networks (CNN), Recurrent Neural Networks (RNN), Auto-encoders, Deep Belief Network, Deep Boltzmann Machines, and each of them may have some sub-variants (Zhao et al., 2019). LSTM is an architecture of RNN which uses past sequences to forecast future data (Moghar and Hamiche, 2020). In LSTM architecture, information flows, including determining which information to remain and how long it persists, are regulated via input, forget, and output gates (Bandara, Bergmeir, and Smyl, 2020). The input, output, and forget gates have different abilities and tasks in the architecture. The input gate can choose information necessary to be stored in the internal state, the output gate has the capability of deciding the output information, and the forget gate can throw away the useless information (Zhang et al., 2017b). LSTM has widely preferred for the predictive analysis of sequential data and has a wide range of application areas, including failure prediction, remaining useful life prediction, voice recognition, time series analysis, document classification (Nabipour et al., 2020). LSTM stands out for its ability to recognize long-term dependencies and patterns in sequential data and provide more successful results of anomaly and failure detections than standard RNN in this data type (Greff et al., 2016; Meyes et al., 2019).

The mathematical expression of LSTM output of the jth cell $\left(c_{j}\right)$ at time $\mathrm{t}$ is given in Equation (3) (Hochreiter and Schmidhuber, 1997; Smagulova and James, 2019):

$y^{c_{j}}(t)=y^{\text {out }}{ }_{j}(t) h\left(s_{c_{j}}(t)\right)$

where $s_{c_{j}}(t)$ is an internal state:

$s_{c_{j}}(t)=y^{\phi_{j}}(t) s_{c_{j}}(t-1)+y^{i n_{j}}(t) g\left(\operatorname{net}_{c j}(t)\right)$

where $y^{\phi_{j}}$ is an output of forget gate:

$y^{\phi_{j}}(t)=f_{\phi_{j}}\left(\right.$ net $\left._{\phi_{j}}\right)$ 
The output values of the output gate $\left(o u t_{j}\right)$ and input gate $\left(i n_{j}\right)$ are given in Equations (6)-(7) (Hochreiter and Schmidhuber, 1997; Smagulova and James, 2019):

$$
\begin{aligned}
& y^{\text {out }_{j}}(t)=f_{\text {out }_{j}}\left(\text { net }_{\text {out }_{j}}\right) \\
& y^{\text {in }}(t)=f_{n_{j}}\left(\text { net }_{\text {in }}\right)
\end{aligned}
$$

Net inputs of a cell are expressed in Equations (8)(10) (Hochreiter and Schmidhuber, 1997; Smagulova and James, 2019): (u: denotes units)

$$
\begin{aligned}
& \operatorname{net}_{\text {out }_{j}}(t)=\sum_{u} w_{\text {out }_{j} u} y^{u}(t-1) \\
& \operatorname{net}_{\text {in }_{j}}(t)=\sum_{u} w_{\text {in }_{j} u} y^{u}(t-1) \\
& \operatorname{net}_{c_{j}}(t)=\sum_{u} w_{c_{j} u} y^{u}(t-1)
\end{aligned}
$$

This study aims to address the multi-class failure classification problem in the plastic extrusion process using the actual sequential process data of an insulation company by applying LSTM, one of the deep learning methods widely known for its successful performance in prediction problems for the sequentially formed datasets, and machine learning methods of MLP and $\mathrm{LR}$, to evaluate and compare the class prediction performance of these approaches.

Even though there have been studies handling the determination of process parameters problem in the plastic extrusion process with machine learning methods (Huang and Liao, 2002; Al Rozuq and Al Robaidi, 2013; Cirak and Kozan, 2009), none studies reached addressing any problems in this process with deep learning. Therefore, this study aims to contribute to the related literature by addressing the failure classification problem in the plastic extrusion process and applying deep learning.

In the next section of this study, some of the relevant related works addressing similar problems by applying LSTM, MLP, and LR are introduced. Afterward, the problem is explained in detail. Following this section, application findings and their analysis are presented. Finally, the results are evaluated and discussed in the conclusion section.

\section{Related Works}

Failure classification and prediction problems have been attracted considerable attention in previous studies. In those studies, wide range of machine learning based methods, including Artificial Neural Networks (ANN) (Dreiseitl and Ohno-Machado, 2002; Gyimothy, Ferenc and Siket, 2005; Singh, Kaur and Malhotra, 2009), CNN (Janssens et al., 2016; Tan and Pan, 2019), Decision Tree (DT) (Dreiseitl and OhnoMachado, 2002; Gyimothy, Ferenc and Siket, 2005; Singh, Kaur and Malhotra, 2009), Deep CNN
(Razaviarab, Sharifi and Banadaki, 2019), k-nearestneighbour (Dreiseitl and Ohno-Machado, 2002), LR (Dreiseitl and Ohno-Machado, 2002; Gyimothy, Ferenc and Siket, 2005; Singh, Kaur and Malhotra, 2009; Malhotra and Singh, 2011), LSTM (Malhotra et al., 2015; Zhang et al., 2017b; Morariu et al., 2018; Tan and Pan, 2019; Ye et al., 2019), MLP (Liukkonen et al., 2009; Kutyłowska, 2015; Hore et al., 2016; Orrù et al., 2020), Random Forest (Tan and Pan, 2019) and Support Vector Machine (SVM) (Dreiseitl and OhnoMachado, 2002; Singh, Kaur and Malhotra, 2009; Zhang et al., 2017a; Oh et al., 2019) have been applied. This section presents indicators and findings related to LSTM, MLP, and LR models for the failure prediction problem used in previous studies.

Zhang et al. (2017b) employed the LSTM-RNN method to predict the battery's remaining useful life with deep learning capability. They compared the LSTM and SVM methods and noted that the LSTMRNN method predictions are more accurate than SVM. Tan and Pan (2019) proposed a model to predict faults of wireless networks based on LSTM and CNN. This study compared CNN, CNN-LSTM, and Random Forest models' performances and showed that their CNN-LSTM hybrid prediction model had better performance than the other applied models. Malhotra et al. (2015) studied the fault prediction problem by applying the stacked LSTM. They used data sets, including power demand, multi-sensor motor, space shuttle. Their results indicated that normal time-series behavior could be modeled with the stacked LSTM. Morariu et al. (2018) used the LSTM approach to estimate energy consumption patterns in the production cycle accurately. They proposed a structure that processes the information flow in high-capacity production systems using map reduction algorithms and focuses on energy consumption with big data concepts collected in various layers. Ye et al. (2019) proposed the LSTM-RNN structure by making parameter estimates for a reasonable estimate of river water quality.

Hore et al. (2016) used the MLP-FFN classifier to predict failures of reinforced concrete buildings. They identified the possibility of failure of the handled buildings in the future. The experimental results obtained in this study indicated that the proposed model provides satisfactory performance. Kutyłowska (2015) developed MLP networks to model the damage frequency in the water supply systems. She noted that the plumbing could use the created model to determine the frequency of breakdowns and plan the replacement of broken pipes. Liukkonen et al. (2009) performed a wave soldering event study to predict product failures using the MLP neural network model. They focused on root causes in response to the number of failures they detected in their work. As the MLP algorithm's input, they accepted the types of failure as the output of the process parameters. Finally, Orrù et al. (2020) applied MLP and SVM for the fault prediction problem using 
real-time collected sensor data from a refinery's production line.

Malhotra and Singh (2011) used the LR and seven other machine learning methods to predict faulty classes with object-oriented metrics in software testing. Singh, Kaur, and Malhotra (2009) compared LR, Artificial Neural Network (ANN), SVM, and DT methods for the fault proneness of object-oriented system classes by using Receiver Operating Characteristic analysis. Gyimothy, Ferenc, and Siket (2005) employed LR, neural network, and DT for fault prediction. The results showed that the logistic regression analysis was significant. Finally, Dreiseitl and Ohno-Machadob (2002) compared LR and ANN methods with other classification algorithms, such as SVM, k-nearest neighbors, and DT.

\section{Problem and Data Description}

Conducting predictive analysis based on process data is one of the prerequisites of today's manufacturing understanding. In this study, the classification problem of multi failure types occurring during the plastic extrusion process of an insulation company has been addressed. Plastic extrusion is a continuous process in which a solid plastic material is converted into a molten fluid; the flowable melt moves into the die and takes the desired shape. The temperature and pressure rollers fed from the top and bottom layers produce a double waterproofing sheet. The line is fed from top layers via extruders A and B, and from bottom layers, via extruder $\mathrm{C}$. There are lower, central, and upper calenders at the end of the die. Finally, the calendered product is cooled and wound in rolls. Extruder $\mathrm{C}$ is used to reprocess granulated plastic waste. For this reason, a filter system is used in Extruder C.

The initial dataset received from the company covers the real measurements taken every 5 minutes sequentially and the failure categories at measurement times. In this process, a number of failure types, including edge tearing, die cleaning, die changing, filter changing, failures of material feeding can occur. However, only filter changes and material feeding failures to the line during the data collection period have occurred. So the failure categories have been labeled as "No failure," "Filter change," and "Feeding failures" in the initial dataset. These categories are coded to be used in the models as follows:

- $\quad$ No failure (0)

- $\quad$ Filter change (1)

- $\quad$ Feeding failures (2)

Some of the parameters' values do not change during the analysis period. Therefore, these parameters were excluded from the analysis. Also, there are some parameters with some missing values. After cleaning the dataset, the final dataset includes 7171 observations regarding seven parameters and failure categories as the target variable. The variables, their descriptions, and ranges are given in Table 1.

Table 1. Description of the variables in the dataset

\begin{tabular}{|c|c|c|c|}
\hline No & Variable Name & Description & Range \\
\hline 1 & $\begin{array}{l}\text { Pane1-Temperature } \\
\text { Central Roll }\left({ }^{\circ} \mathrm{C}\right)\end{array}$ & $\begin{array}{l}\text { Temperature of the } \\
\text { central roll }\end{array}$ & {$[9.500,57.089]$} \\
\hline 2 & $\begin{array}{l}\text { Pane1-Temperature } \\
\text { Lower Roll }\left({ }^{\circ} \mathrm{C}\right)\end{array}$ & $\begin{array}{l}\text { Temperature of the } \\
\text { lower roll }\end{array}$ & {$[9.619,68.725]$} \\
\hline 3 & $\begin{array}{l}\text { Pane1-Temperature } \\
\text { Upper Roll }\left({ }^{\circ} \mathrm{C}\right)\end{array}$ & $\begin{array}{l}\text { Temperature of the } \\
\text { upper roll }\end{array}$ & {$[10.363,58.945]$} \\
\hline 4 & $\begin{array}{l}\text { Pane1-Melt } \\
\text { Temp. A }\left({ }^{\circ} \mathrm{C}\right)\end{array}$ & $\begin{array}{l}\text { Melt temperature } \\
\text { of } \\
\text { extruder A }\end{array}$ & {$[8.766,196.181]$} \\
\hline 5 & $\begin{array}{l}\text { Pane1-Melt, } \\
\text { Temp. B }\left({ }^{\circ} \mathrm{C}\right)\end{array}$ & $\begin{array}{l}\text { Melt temperature } \\
\text { of } \\
\text { extruder B }\end{array}$ & {$[9.530,195.107]$} \\
\hline 6 & $\begin{array}{l}\text { Pane1-Melt } \\
\text { Temp. C }\left({ }^{\circ} \mathrm{C}\right)\end{array}$ & $\begin{array}{l}\text { Melt temperature } \\
\text { of } \\
\text { extruder } \mathrm{C}\end{array}$ & {$[11.527,197.047]$} \\
\hline 7 & $\begin{array}{l}\text { Ext. C. melt } \\
\text { pressure_difference } \\
\left({ }^{\circ} \mathrm{C}\right)\end{array}$ & $\begin{array}{l}\text { Difference of the } \\
\text { two consecutive } \\
\text { melt pressures in } \\
\text { extruder C }\end{array}$ & {$[-157.937,223.702]$} \\
\hline
\end{tabular}

\section{Application and Findings}

This study has addressed the multi-class failure classification problem using actual measurement data taken from the plastic extrusion process of an insulation company with LSTM, MLP, and LR. The performance of LSTM depends on the values of its hyperparameters. Since there is no exact way of choosing which hyperparameter values work best, one of the most frequently followed methods is to use some combinations of parameters and test these combinations' performances with several experiments (Greff et al., 2016).

In this study, the analysis-ready data set was randomly divided into training, validation, and testing sets with the size of $70 \%, 20 \%$, and $10 \%$ of the whole data set, respectively. Therefore, the fault categories' observations into the training, validation and testing sets are as equal as possible. In Table 2, features of the training, validation, and testing sets are presented.

Table 2. Features of the training, validation, and testing sets

\begin{tabular}{lc}
\hline \multicolumn{1}{c}{ Number (percentage) of } & No failure: 4675 \\
failure categories in the training & $(94.79 \%)$ \\
set & Filter change: 6 \\
& $(0.12 \%)$ \\
& Feeding failure: \\
& $251(5.09 \%)$
\end{tabular}

\begin{tabular}{lc}
\multicolumn{1}{c}{ Training set size } & 4932 \\
\hline Number (percentage) of & No failure: 1441 \\
failure categories in the & $(95.43 \%)$ \\
validation set & Filter change: 3 \\
& $(0.20 \%)$ \\
& Feeding failure: 66 \\
& $(4.37 \%)$ \\
Validation set size & 1510 \\
\hline Number (percentage) of & No failure: 695 \\
failure categories in the testing & $(95.34 \%)$
\end{tabular}




\begin{tabular}{lc}
\hline set & Filter change: 2 \\
& $(0.27 \%)$ \\
& Feeding failure: 32 \\
Testing set size & $(4.39 \%)$ \\
\hline
\end{tabular}

Before implementing the analyzed methods, all inputs were normalized. In normalization, firstly, minmax and z-score normalization techniques are among the most widely used normalization techniques. The classification performance of MLP and LSTM have indicated that these models have better performance with the data normalized by the $z$-score technique. Therefore, the $\mathrm{z}$-score normalization technique has been selected, and the results obtained with the z-score normalized data set have been presented in the rest of the study. This study followed the methodology of training models, running the trained models with multiple parameter settings several times by using the validation set and finally evaluating the models' performances in the testing set. Depending on the dataset's highly unbalanced structure, the performance of the methods is evaluated by employing evaluation metrics of precision, recall, and F1 score for each category. In addition to these metrics, the overall accuracy of the methods' predictions is also computed and compared. All employed metrics' formulas are given in Equations (11)-(14) (Orrù et al., 2020):

$$
\begin{aligned}
& \text { Overall Accuracy }=\frac{\mathrm{TP}+\mathrm{TN}}{\mathrm{TP}+\mathrm{FP}+\mathrm{TN}+\mathrm{FN}} \\
& \text { Precision }=\frac{\mathrm{TP}}{\mathrm{TP}+\mathrm{FP}} \\
& \text { Recall }=\frac{\mathrm{TP}}{\mathrm{TP}+\mathrm{FN}} \\
& \mathrm{F} 1 \text { Score }=2 \times \frac{(\text { Precision } \times \text { Recall })}{(\text { Precision }+ \text { Recall })}
\end{aligned}
$$

(TP: True positives, TN: True negatives, FP: False positives, and FN: False negatives)

In LSTM and MLP models, batch size, epoch, learning rate, dropout rate, and optimizer type combinations seen in Table 3 are run ten times in the validation set, and the combination that gives the best result among these combinations is employed in the testing set. All models are coded in R.

Table 3. Parameters in the experiments

\begin{tabular}{ll}
\hline Parameters & Value \\
\hline Output Units & 3 \\
Batch Size & $4,8,16,32,64$ \\
Epoch & $10,20,50,100$ \\
Optimizer & RMSprop, adam \\
Learning Rate & $0.001,0.0001$ \\
Dropout Rate & $0.02,0.2$ \\
\hline
\end{tabular}

Confusion matrices of the models are presented in Figures 1-3. Overall accuracies of the applied methods are given in the lower right corner of the matrices. Moreover, at the rightest column and in the bottom row, recall and precision values of the methods on each failure category are presented, respectively.

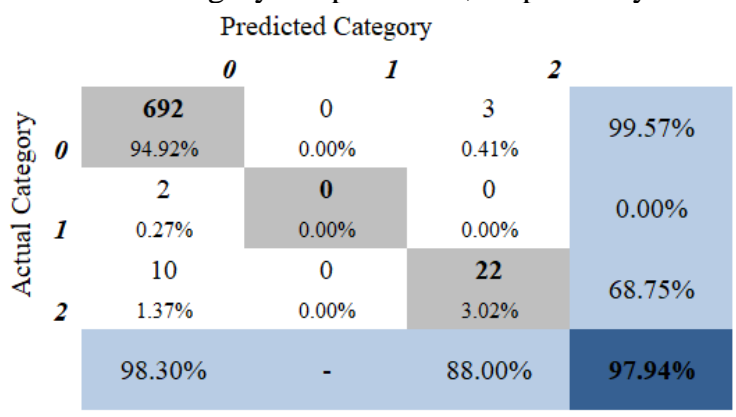

Figure 1. Confusion matrix of LR

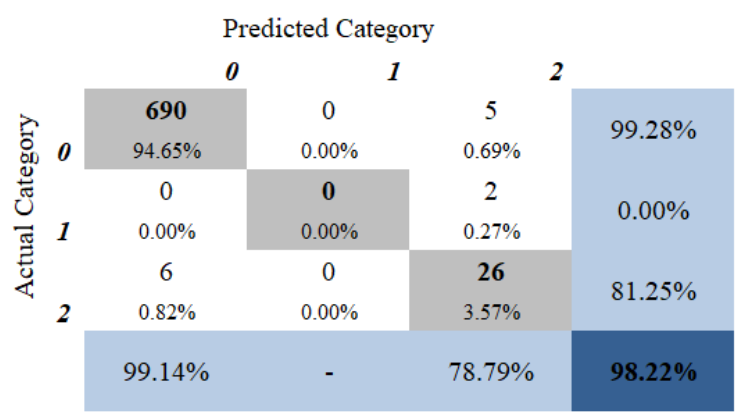

Figure 2. Confusion matrix of MLP

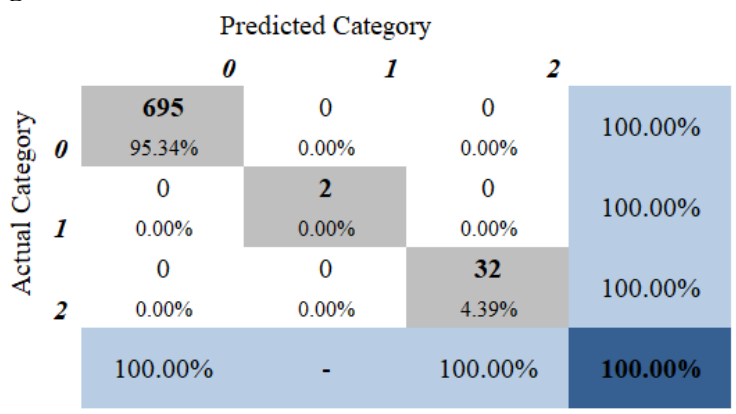

Figure 3. Confusion matrix of LSTM

All applied methods have reached a high overall accuracy. LSTM is the best with $100 \%$ accuracy, while LR is the last with $97.94 \%$ accuracy. Performances of the applied methods in terms of precision, recall, and F1 Score evaluation metrics are presented in Table 4. The results have indicated that LSTM has $100 \%$ performance for each category for each evaluation metric. The most important point revealing the success of LSTM is that it accurately predicts the class of Category 1 (Filter change), which occurs only twice in the whole test set. LR and MLP have been inadequate to predict the class of these two observations in Category 1 . LR has predicted Category 1 as Category 0 (No failure), while MLP has predicted Category 2 
(Feeding failure). The precision of LP and MLP for Category 1 is obtained as undefined from 0 divided by 0 . Therefore, F1 Scores cannot be calculated.

Both LR and MLP have reached high precision, recall, and F1 Score over Category 0. However, MLP has better precision and F1 Score for Category 0 than LR, while LR has a higher recall value over Category 0 than MLP. Therefore, in parallel with this study's aim, to test and compare LR and MLP performances, it is more appropriate to emphasize Category 2 (Feeding failure) rather than Category 0.

LR has achieved a higher precision value over Category 2 than MLP. This result has revealed that the portion of the classes that LR predicts as Category 2 actually to be Category 2 is higher than MLP. On the other hand, MLP has yielded more successful results than LR in recall and F1 Score for Category 2. It implies that the ratio of actual "Feeding failure" detected correctly by MLP is higher than LR.
A 5-fold cross-validation procedure has been carried out to assess the validity of the models. As a result, the overall accuracy of LR, MLP, and LSTM methods have been obtained as $97.89 \%, 98.76 \%$, and $99.26 \%$, respectively.

In addition to overall accuracy, precision, recall, and F1 score for each category for each method have been calculated. The results presented in Table 5 indicate that LSTM has the best performance for all metrics. For example, while LR and MLP could not detect any observations of Category 1, LSTM has correctly predicted $66.67 \%$ of Category 1 observations.

The results of 5-fold cross-validation have also confirmed that LSTM has the most successful performance in all failure categories for the problem examined in this study.

Table 4 Prediction performances of the methods on the testing set

\begin{tabular}{cccccccccc}
\hline & & LR & & & MLP & & \multicolumn{2}{c}{ LSTM } \\
Category & Precision & Recall & F1 Score & Precision & Recall & F1 Score & Precision & Recall & F1 Score \\
\hline 0 & $98.30 \%$ & $99.57 \%$ & $98.93 \%$ & $99.14 \%$ & $99.28 \%$ & $99.21 \%$ & $100.00 \%$ & $100.00 \%$ & $100.00 \%$ \\
1 & - & $0.00 \%$ & - & - & $0.00 \%$ & - & $100.00 \%$ & $100.00 \%$ & $100.00 \%$ \\
2 & $88.00 \%$ & $68.75 \%$ & $77.19 \%$ & $78.79 \%$ & $81.25 \%$ & $80.00 \%$ & $100.00 \%$ & $100.00 \%$ & $100.00 \%$ \\
\hline
\end{tabular}

Table 5. Prediction performances of the methods with 5-fold cross-validation

\begin{tabular}{cccccccccc}
\hline & \multicolumn{3}{c}{ LR } & & \multicolumn{3}{c}{ MLP } & & \multicolumn{2}{c}{ LSTM } \\
Category & Precision & Recall & F1 Score & Precision & Recall & F1 Score & Precision & Recall & F1 Score \\
\hline 0 & $98.55 \%$ & $99.25 \%$ & $98.90 \%$ & $99.16 \%$ & $99.60 \%$ & $99.38 \%$ & $99.52 \%$ & $99.77 \%$ & $99.64 \%$ \\
1 & - & $0.00 \%$ & - & - & $0.00 \%$ & - & $66.67 \%$ & $77.78 \%$ & $68.89 \%$ \\
2 & $82.87 \%$ & $72.69 \%$ & $77.25 \%$ & $91.31 \%$ & $84.35 \%$ & $86.87 \%$ & $94.86 \%$ & $90.24 \%$ & $92.30 \%$ \\
\hline
\end{tabular}

\section{Conclusions}

This study addresses the problem of failure classification, which takes an important role in our age's manufacturing vision, based on the actual process data. The problem's application is conducted using the actual process data obtained from the plastic extrusion process of an insulation company. The study aims to contribute to the literature by addressing the failure classification problem in the plastic extrusion process and applying a deep learning method, LSTM, to the problem. In addition to LSTM, machine learning methods of MLP and LR are also applied, and performances of the models are compared based on accuracy, precision, recall, and F1 Score measures.

The models' class prediction accuracy has been obtained within a high range of $97.94 \%$ (LR) and $100.00 \%$ (LSTM). LSTM has classified all failure categories correctly. LR and MLP have reached a considerable and close performance in classifying Category 0 and Category 2, but they have been insufficient to predict the class of Category 1.
LSTM, as a deep learning method, has performed better than the considered machine learning methods and had $100 \%$ accuracy even though the problem dataset contains an extremely low number of Failure-1 observations. Further studies might test the models with larger datasets, including sufficient failure observations and more process parameters.

\section{References}

Al Rozuq, R. A. M. I., Al Robaidi, A. M. I. N. 2013. Application of neural network ANN to predict XLPE cable in extrusion processes. Journal of Materials Sciences and Applications, 2013.

Bandara, K., Bergmeir, C., Smyl, S. 2020. Forecasting across time series databases using recurrent neural networks on groups of similar series: A clustering approach. Expert Systems with Applications, 140, 112896.

Cadavid, J. P. U., Lamouri, S., Grabot, B., Pellerin, R., Fortin, A. 2020. Machine learning applied in production planning and control: a state-of-the-art in the era of industry 4.0. Journal of Intelligent Manufacturing, 1-28.

Caesarendra, W., Widodo, A., Yang, B. S. 2010. Application of relevance vector machine and logistic regression for 
machine degradation assessment. Mechanical Systems and Signal Processing, 244, 1161-1171.

Cirak, B., Kozan, R. 2009. Prediction of the coating thickness of wire coating extrusion processes using artificial neural network ANN. Modern Applied Science, 37, 52-66.

De Menezes, F. S., Liska, G. R., Cirillo, M. A., Vivanco, M. J. 2017. Data classification with binary response through the Boosting algorithm and logistic regression. Expert Systems with Applications, 69, 62-73.

Dreiseitl, S., Ohno-Machado, L. 2002. Logistic regression and artificial neural network classification models: a methodology review. Journal of biomedical informatics, 355-6, 352-359.

Fallah, N., Mitnitski, A., Rockwood, K. 2011. Applying neural network Poisson regression to predict cognitive score changes. Journal of Applied Statistics, 389, 20512062.

Greff, K., Srivastava, R. K., Koutník, J., Steunebrink, B. R., Schmidhuber, J. 2016. LSTM: A search space odyssey. IEEE transactions on neural networks and learning systems, 2810, 2222-2232.

Gyimothy, T., Ferenc, R., Siket, I. 2005. Empirical validation of object-oriented metrics on open source software for fault prediction. IEEE Transactions on Software engineering, 3110, 897-910.

Hochreiter, S., Schmidhuber, J. 1997. Long short-term memory. Neural computation, 9(8), 1735-1780.

Hore, S., Chatterjee, S., Sarkar, S., Dey, N., Ashour, A. S., Balas-Timar, D., Balas, V. E. 2016. Neural-based prediction of structural failure of multistoried RC buildings. Structural Engineering and Mechanics, 583, 459-473.

Hou, T. H. T., Liu, W. L., Lin, L. 2003. Intelligent remote monitoring and diagnosis of manufacturing processes using an integrated approach of neural networks and rough sets. Journal of Intelligent Manufacturing, 142, 239-253.

Huang, H. X., Liao, C. M. 2002. Prediction of parison swell in plastics extrusion blow molding using a neural network method. Polymer testing, 217, 745-749.

Janssens, O., Slavkovikj, V., Vervisch, B., Stockman, K., Loccufier, M., Verstockt, S., de Walle, R.V. Van Hoecke, S. 2016. Convolutional neural network based fault detection for rotating machinery. Journal of Sound and Vibration, 377, 331-345.

Jing, C., Hou, J. 2015. SVM and PCA based fault classification approaches for complicated industrial process. Neurocomputing, 167, 636-642.

Jing, L., Zhao, M., Li, P., Xu, X. 2017. A convolutional neural network based feature learning and fault diagnosis method for the condition monitoring of gearbox. Measurement, 111, 1-10.

Konar, P., Chattopadhyay, P. 2011. Bearing fault detection of induction motor using wavelet and Support Vector Machines SVMs. Applied Soft Computing, 116, 42034211.

Kutyłowska, M. 2015. Neural network approach for failure rate prediction. Engineering Failure Analysis, 47, 41-48.

Le Thi, H. A., Le, H. M., Phan, D. N., \& Tran, B. 2020. Stochastic DCA for minimizing a large sum of DC functions with application to multi-class logistic regression. Neural Networks, 132, 220-231.

Liukkonen, M., Hiltunen, T., Havia, E., Leinonen, H., Hiltunen, Y. 2009. Modeling of soldering quality by using artificial neural networks. IEEE Transactions on electronics packaging manufacturing, 322, 89-96.

Malhotra, P., Vig, L., Shroff, G., Agarwal, P. 2015., Long short term memory networks for anomaly detection in time series, Proceedings of European Symposium on Artificial Neural Networks, Computational Intelligence and Machine Learning, Presses universitaires de Louvain. 22-24 April 2015, pp. 89-94.

Malhotra, R., Singh, Y. 2011. On the applicability of machine learning techniques for object oriented software fault prediction. Software Engineering: An International Journal, 11, 24-37.

Meyes, R., Donauer, J., Schmeing, A., Meisen, T. 2019. A Recurrent Neural Network Architecture for Failure Prediction in Deep Drawing Sensory Time Series Data. Procedia Manufacturing, 34, 789-797.

Moghar, A., Hamiche, M. 2020. Stock market prediction using LSTM recurrent neural network. Procedia Computer Science, 170, 1168-1173.

Morariu, C., Răileanu, S., Borangiu, T., Anton, F. 2018, June. A distributed approach for machine learning in large scale manufacturing systems. In International Workshop on Service Orientation in Holonic and Multi-Agent Manufacturing pp. 41-52. Springer, Cham.

Nabipour, M., Nayyeri, P., Jabani, H., Shahab, S., Mosavi, A. 2020. Predicting stock market trends using machine learning and deep learning algorithms via continuous and binary data; a comparative analysis. IEEE Access, 8 , 150199-150212.

Oh, Y., Ransikarbum, K., Busogi, M., Kwon, D., Kim, N. 2019. Adaptive SVM-based real-time quality assessment for primer-sealer dispensing process of sunroof assembly line. Reliability Engineering System Safety, 184, 202212.

Orrù, P. F., Zoccheddu, A., Sassu, L., Mattia, C., Cozza, R., Arena, S. 2020. Machine learning approach using MLP and SVM algorithms for the fault prediction of a centrifugal pump in the oil and gas industry. Sustainability, 12(11), 4776.

Quintana, G., Garcia-Romeu, M. L., Ciurana, J. 2011. Surface roughness monitoring application based on artificial neural networks for ball-end milling operations. Journal of Intelligent Manufacturing, 224, 607-617.

Razaviarab, N., Sharifi, S., Banadaki, Y. M. 2019. Smart additive manufacturing empowered by a closed-loop machine learning algorithm, In Nano-, Bio-, Info-Tech Sensors and 3D Systems III, International Society for Optics and Photonics, Vol. 10969 2009, p. 109690H.

Shao, S. Y., Sun, W. J., Yan, R. Q., Wang, P., Gao, R. X. 2017. A deep learning approach for fault diagnosis of induction motors in manufacturing. Chinese Journal of Mechanical Engineering, 306, 1347-1356.

Singh, Y., Kaur, A., Malhotra, R. 2009. Comparative analysis of regression and machine learning methods for predicting fault proneness models. International journal of computer applications in technology, 352-4, 183-193. 
Smagulova, K., \& James, A. P. 2019. A survey on LSTM memristive neural network architectures and applications. The European Physical Journal Special Topics, 228(10), 2313-2324.

Tan, Z., Pan, P. 2019. Network Fault Prediction Based on CNN-LSTM Hybrid Neural Network. In 2019 International Conference on Communications, Information System and Computer Engineering CISCE pp. 486-490. IEEE.

Tao, F., Qi, Q., Liu, A., Kusiak, A. 2018. Data-driven smart manufacturing. Journal of Manufacturing Systems, 48, 157-169.

Venkatesan, P., \& Anitha, S. 2006. Application of a radial basis function neural network for diagnosis of diabetes mellitus. Current Science, 91(9), 1195-1199.

Wang, J., Ma, Y., Zhang, L., Gao, R. X., Wu, D. 2018. Deep learning for smart manufacturing: Methods and applications. Journal of Manufacturing Systems, 48, 144156.

Ye, Q., Yang, X., Chen, C., Wang, J. 2019. River Water Quality Parameters Prediction Method Based on LSTMRNN Model. In 2019 Chinese Control And Decision Conference CCDC pp. 3024-3028. IEEE.

Yilmaz, I., Kaynar, O. 2011. Multiple regression, ANN (RBF, MLP) and ANFIS models for prediction of swell potential of clayey soils. Expert systems with applications, 38(5), 5958-5966.

Zhang, S., Wang, Y., Liu, M., Bao, Z. 2017a. Data-based line trip fault prediction in power systems using LSTM networks and SVM. IEEE Access, 6, 7675-7686.

Zhang, Y., Xiong, R., He, H., Liu, Z. 2017b, July. A LSTMRNN method for the lithuim-ion battery remaining useful life prediction. In 2017 Prognostics and System Health Management Conference PHM-Harbin pp. 1-4. IEEE.

Zhao, R., Yan, R., Chen, Z., Mao, K., Wang, P., Gao, R. X. 2019. Deep learning and its applications to machine health monitoring. Mechanical Systems and Signal Processing, 115, 213-237. 